\title{
The Uses of Sediment Transport and Morphodynamic Modeling in Stream Restoration \\ G. Parker ${ }^{1,2}$
}

${ }^{1}$ National Center for Earth-surface Dynamics, St. Anthony Falls Laboratory, Department of Civil Engineering, University of Minnesota, \#2 $3^{\text {rd }}$ Ave SE, Minneapolis, MN 55414; PH (612)624-4363; FAX (612)624-4609; email: 2parke002@umn.edu

\section{Abstract (number)}

Many streams have become morphologically and ecologically compromised because their sediment budget is out of balance. Examples include a) stream reaches upstream and downstream of dams, b) streams subject to gravel/sand mining, c) streams subject to urban encroachment, d) streams the drainage basins of which have been made largely impermeable and e) streams subject to sediment disposal, toxic or otherwise. Restoration of such streams can be greatly aided by considerations of sediment balance. Depending on the type of project under consideration, the calculations involved can be as simple as those implemented with a spreadsheet or

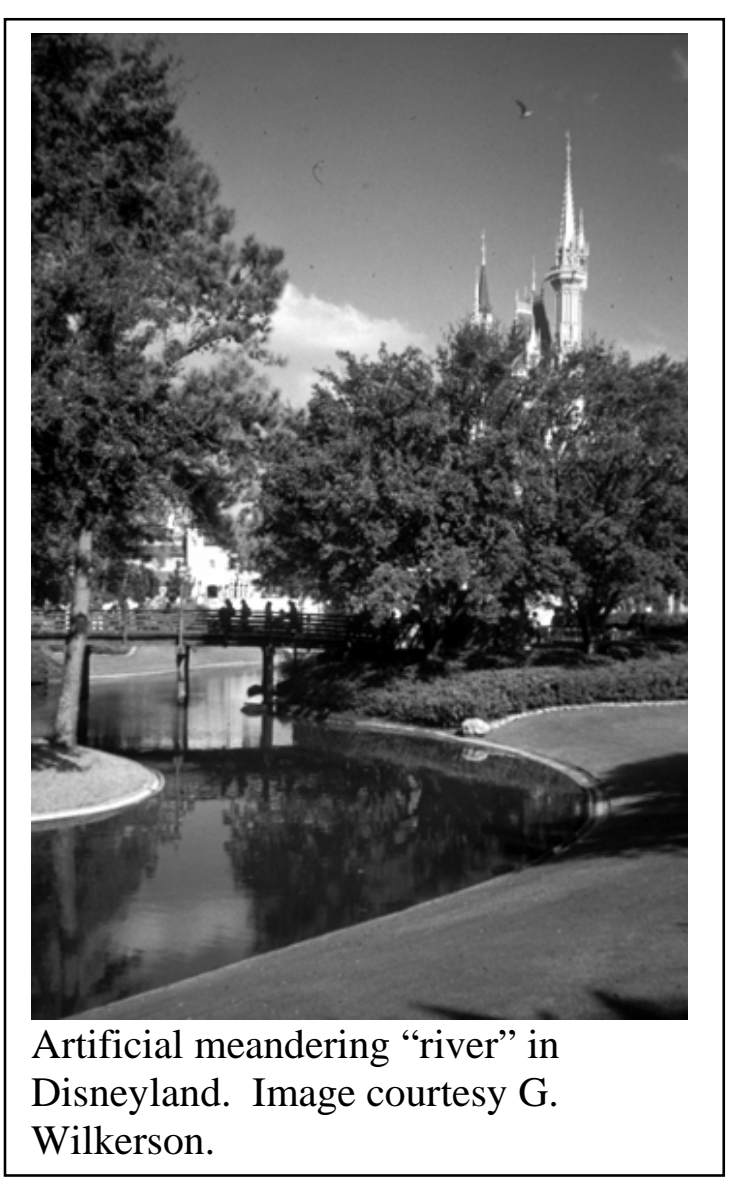

sufficiently complex to require a custom-made numerical model. An example is given in the presentation.

\section{Introduction: Disneylandification and self-restoration}

River restoration is very much in fashion as of 2004. Like many fashions, it has a tendency to be pursued with admirable zeal but sometimes less than thorough introspection. The word "restoration" implies the return of a state that previously prevailed under "natural" conditions but no longer prevails due to anthropogenic effects. Yet in many cases this antecedent state is either poorly known or unknowable. In such circumstances river "restoration" can devolve into the artificial construction of streams that are perceived to be appealing to the public. An example of such a case is when a stream that never had a native population of trout is "restored" to provide habitat for introduced trout. This process might be 


\section{Proceedings, ASCE World Water and Environmental Resources 2004 Congress, Salt Lake City, June 27-July 1, 10 p.}

called "Disneylandification" rather than "stream restoration," as illustrated by the aesthetically pleasing but entirely artificial meandering "river" illustrated in Figure 1.

A way to view stream restoration that may be more useful and enduring than the issues of aesthetics or public perception is the restoration of lost function to a river. An example of a river with lost functionality is one that no longer has access to its floodplain due to the construction of levees hard up against both banks. The river has lost hydraulic functionality in that there is no accessible floodplain to damp floodwaves as they proceed down the river. As a result, flood peaks can be amplified, so increasing the disaster in the event that the levees are breached or overtopped. The river has lost functionality in terms of sediment balance because a) bed material load is intensified by the confined flood flows, inducing bed degradation and b) fine-grained sediment can no longer deposit overbank. Functionality has been lost from the point of nutrient balance because floodplain sediments are no longer renewed. Functionality has been lost in terms of habitat because a major refuge from predators and rearing ground for juveniles has been lost.

As is seen from the above example, a proper understanding of loss of function and its restoration includes understanding of a) river hydraulics, b) sediment transport, c) river and floodplain morphology, d) riparian nutrient cycling and e) riparian ecosystems and food web dynamics. Perhaps most essential is an understanding of how a functional river has evolved to be that way.

The zealous pursuit of river restoration without the insight of technical knowledge, while laudable in and of itself, does not always yield successful results. The classic example observed by the author is when well-meaning attempts are made to "restore" the meander bends of a river that has been straightened. The desired geometry is inscribed using a sine-generated curve, the channel is excavated to what is deemed to be an appropriate depth, the banks are shaped and stabilized with biodegradable geotextiles and coconut matting, the floodplain is covered with sod and vegetation is planted. It often takes only one good flood for the river to change its configuration entirely, cutting off those carefully shaped bends, making new channels across the floodplain, and leaving the coconut matting strewn about in tatters.

The problem here is based on a simple misunderstanding of river functionality as it pertains to meandering. There is no "ideal shape" to which meander bends tend in the absence of interference. Their fate is to grow, cut off, reform and grow in a cyclic but non-repeating fashion. Left to their own devices, rivers will usually "design" their channels so that these changes occur incrementally. When a meander pattern is forced upon them, however, they only rarely decide to use this as a basis for gradual change. Instead, they often leave it in shreds.

A slower approach that is likely to be far more successful is the restoration of conditions that are conducive to a meandering channel. Once this is done, the river can be left to do the rest of the work in its own way and at its own pace. For example, straightened rivers often degrade into their beds. The resulting high banks inhibit stream migration. Restoring the river bed to its former elevation with the use of well-placed drop structures, combined with a few well-placed low-amplitude "starter bends" can initiate the process of self-restoration.

The above approach is not always possible. More direct intervention may be required in the case of a stream which has lost most of its flood flows due diversion 
for consumptive purposes. This notwithstanding, wherever possible the goal should be to create conditions conducive to allowing the river to self-restore. For example, in the long run it may be far more effective to change dam operation so as to allow at least some flood flow than it is to construct (and then constantly repair) artificial spawning grounds and riffles that the river would construct on its own if given the freedom to do so.

The zealous pursuit of river restoration by non-specialists is often matched by the zealous criticism of such restoration by some academic specialists who show little proclivity to place their expertise in a form that could actually be used by practitioners. The large body of knowledge pertaining to hydraulics, sediment transport, river morphology, nutrient cycling and riparian ecosystems needs to be consolidated and simplified as much as possible (but not too much) so as to both elevate the philosophy and improve the quality of river restoration efforts.

The author's area of expertise is the modeling of sediment transport in rivers and river morphodynamics. These modeling techniques are not used as often as they might be in river restoration. As noted above, the problem is not just because many practitioners may not be aware of them, but also because the specialists may not have done enough to make them available to practitioners. With this in mind, several examples are given below.

\section{Dam removal}

A central element of river restoration is dam removal. Dams all over the world are filling with sediment and losing their functionality. Before they fill with sediment they play useful roles in controlling floods, providing sources of water for consumption and generating clean hydropower. This notwithstanding, they block the migration of fish and radically change river morphology and riparian ecosystems both upstream and downstream of the dam. Once the dam is filled with sediment, nearly all the positive aspects are lost, while all the negative aspects remain or are amplified.

So the removal of a dam offers the chance for a considerable length of stream to be restored, both upstream and downstream. But how should the dam be removed? Two approaches have been popularized in recent years, the "blow and go" of sudden removal and the staged removal. Debate about the possible effects of either sudden or staged removal has led to examples where the all of the sediment in the reservoir has been removed artificially before the dam has been removed. A case in point is Saeltzer Dam, California, shown in Figure 2. 


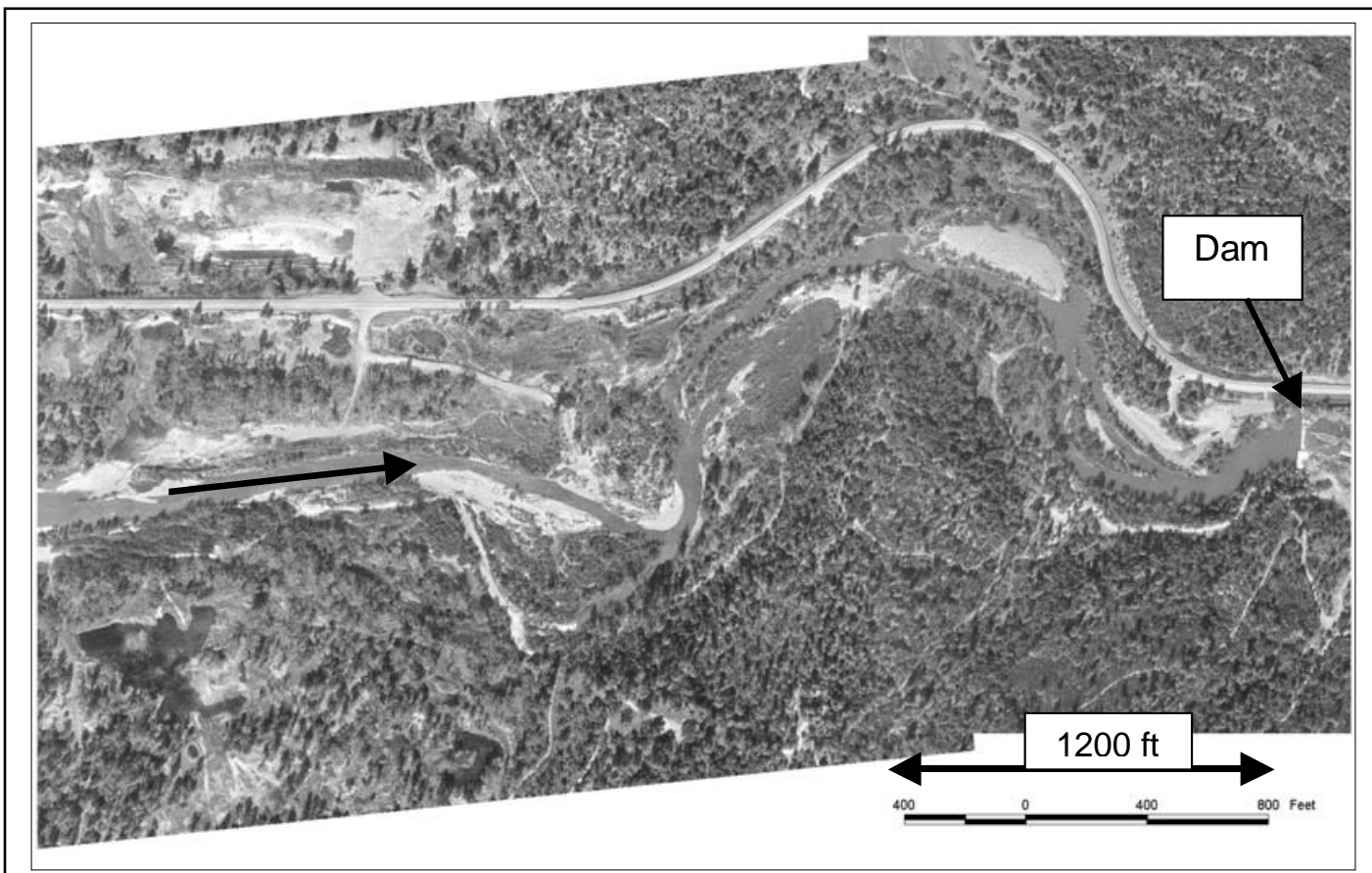

Figure 2. Saeltzer Dam and reservoir, California, before dam removal. Image courtesy Y. Cui.

The artificial removal of all the sediment from the dam was undoubtedly at least partially motivated by concerns about possible deleterious effects were the sediment to be released downstream. One cannot help but point out at the same time that contractors stand to make more money in the event that a total excavation is ordered.

The question as to the disposition of the sediment in the reservoir were the dam to be removed was, however, answerable to a large degree. Recent experience with the response of the Navarro River, California to the input of sediment from a landslide (Figure 3; Lisle et al., 2001) has been one of several driving factors leading to a set of numerical models that are well-suited to describing the disposition of sediment pulses in rivers (Cui et al., 2003a, 2003b). Recently these models have been further adapted into the "DREAM"

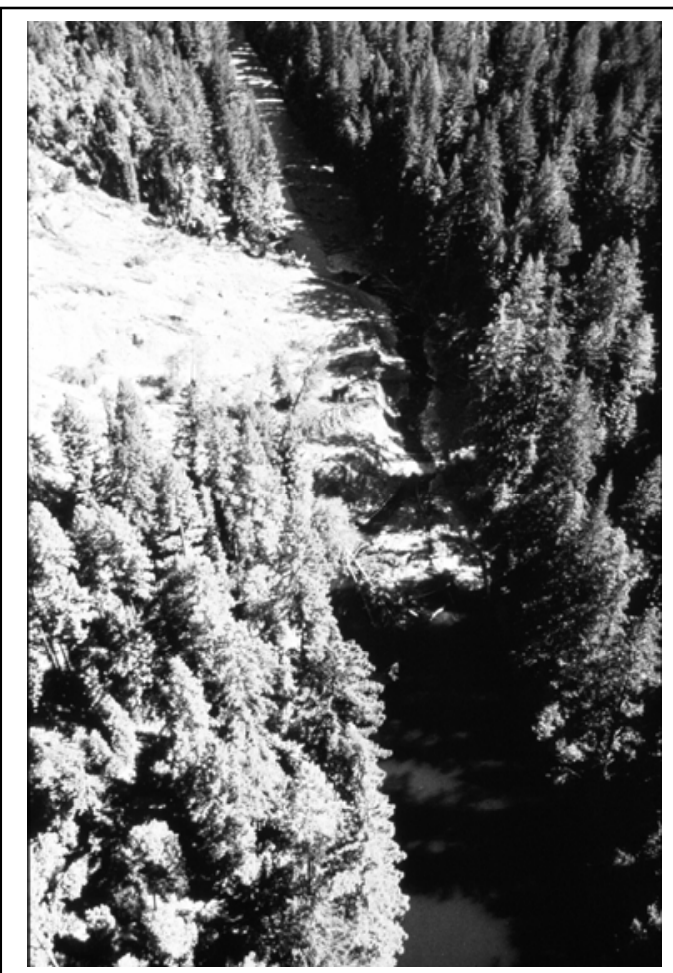

Figure 3. Landslide into the Navarro River, California. Image courtesy T. Lisle. 


\section{Proceedings, ASCE World Water and Environmental Resources 2004 Congress, Salt Lake City, June 27-July 1, 10 p.}

(Dam Removal Express Assessment Models) suite that is expressly designed to predict how sediment is evacuated from a dam after removal (Cui et al., in press-a, in press-b). The models can address questions in regard to both the location and the residence time of the resulting downstream deposits.

The DREAM models in and of themselves cannot answer all questions related to dam removal. Do the sediments contain contaminants, and in what concentrations? How resilient are the resident species to a spike of high sediment concentration? Is a single strong spike over a short period due to "blow and go" or a series of weaker spikes over a longer period likely to be more deleterious to stream ecology? Model results thus need to be analyzed in consonance with input from experts in the areas of water chemistry and riparian ecology. Having said this, sediment modeling offers a way to optimize the technology for dam removal so as to a) save money and b) minimize deleterious effects and maximize beneficial effects.

\section{Gravel mining}

Rivers provide a ready and cheap source for the "gravel" (shorthand for gravel and sand) used in concrete aggregate. As a result, rivers all over the world have been subjected to gravel extraction. Excessive gravel extraction in some stream has led to channel degradation, deterioration of spawning habitat and loss of the connection between the channel and the floodplain, which is rendered a terrace. Stream degradation induced by gravel mining in the Mad River, California is illustrated in Figure 4. Gravel mining was taking place within a few hundred meters of the bridge pier at the time the photo was taken.

One of the easiest ways to "restore" rivers deleteriously affected by gravel mining is to stop removing excessive amounts of gravel. This does not mean that gravel is not available for extraction. Like other resources in limited supply, however, the process must be managed. Part and parcel of this management should be the construction and maintenance of sediment budgets for such streams.

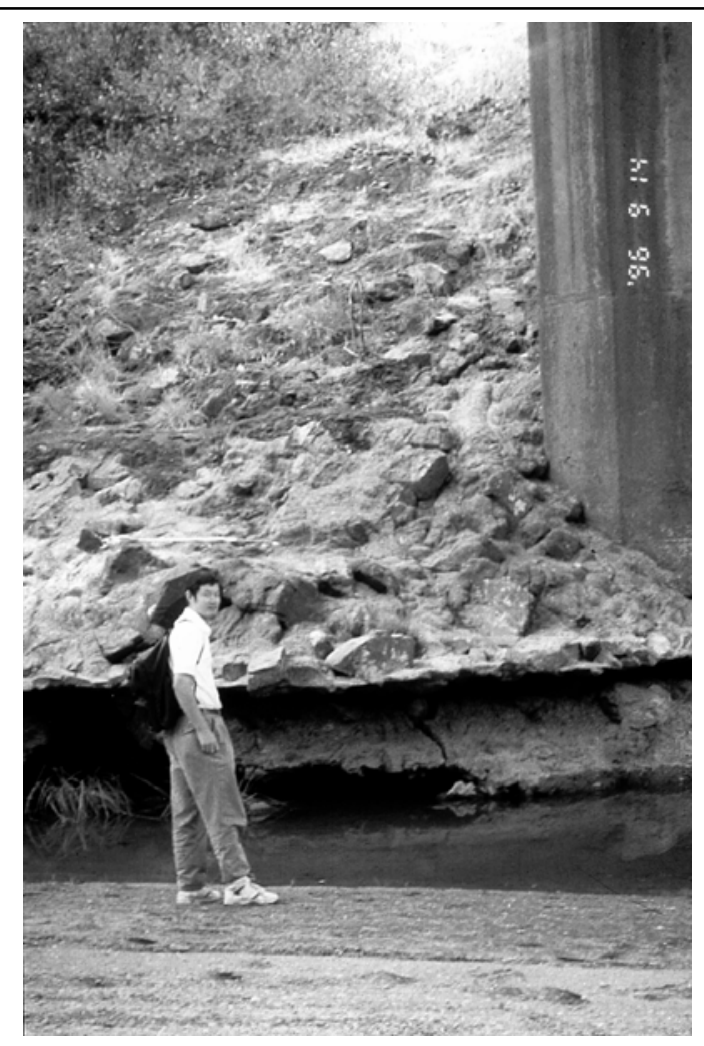

Figure 4. River bed degradation at a bridge pier in the Mad River, California. The photo was taken by the author. Y. Cui serves for scale.

One element of such budgets is a good model for routing sediment through a river, and a good model requires a good transport relation. Earlier models for the transport of gravel and gravel-sand mixtures were not particularly accurate. The author cites four more recent models that ought to provide a good basis for such modeling: Parker (1991); Powell et al. (2001), 


\section{Proceedings, ASCE World Water and Environmental Resources 2004 Congress, Salt Lake City, June 27-July 1, 10 p.}

Hunziker and Jaeggi (2002) and Wilcock and Crowe (2003). The last of these is used in an example below.

The construction and maintenance of sediment budgets for streams, and the management of gravel extraction so as to prevent too much of an imbalance, should allow streams to restore themselves. Given the necessary sediment and competent flows, they will construct their own diverse habitats where natural fauna and flora can flourish.

\section{Urban streams}

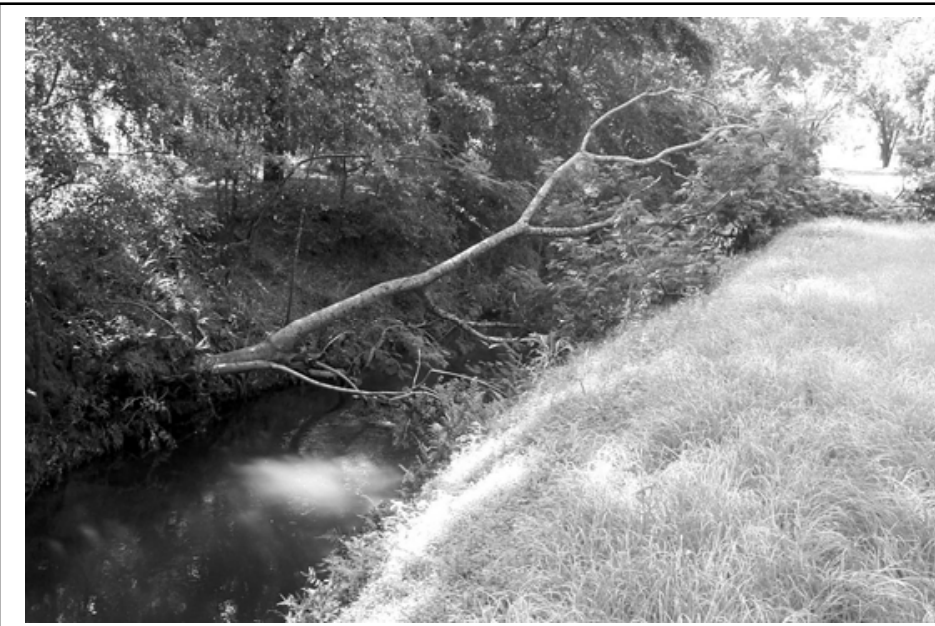

Figure 5. Degrading reach of the Little Wekiva River, Florida before remediation.
Urban streams represent one of the biggest challenges in successful river restoration. Urbanization renders the watershed relatively impermeable, so decreasing the time of concentration and thus the severity of floods. These flood peaks are capable of moving more sediment than in the natural setting. The same urbanization that makes the watershed relatively impermeable can also, however, cut off the natural source of bed material load to the river. The river responds by degrading, and mining sediment from its banks. The resulting bank failure can directly affect houses that have often been built directly on the floodplain and even adjacent to the stream.

Some years ago the author participated in a team of specialists working to stabilize and restore some functionality to the Little Wekiva River north of Orlando, Florida. Urbanization had caused serious channel degradation upstream and aggradation downstream. Many of the more popular techniques of river restoration, including restoration floodplain functionality and bank protection using natural vegetation, could not be fully implemented due to the proximity of houses. Further degradation has been halted, however, with a series of drop structures which serve to stabilize the long profile. The drop structures, combined with a combination of hard and soft bank protection, allow for some renaturalization in an otherwise uncompromising setting. The entire plan was implemented in conjunction with the application of numerical models for both flood and sediment routing, which helped optimize (and thus minimize) the placement of hard control structures.

\section{Levee setback}

In contrast to urban settings, some rural settings offer unprecedented opportunities for river restoration by the simple and effective means of levee setback. 


\section{Proceedings, ASCE World Water and Environmental Resources 2004 Congress, Salt Lake City, June 27-July 1, 10 p.}

A case in point is the valley of the Red River, Minnesota (and adjacent North and South Dakota). The Wild Rice River flows from an upland region into the old bed of Glacial Lake Agassiz, and thence into the Red River. In its natural state, the lower Wild Rice River tended to aggrade and avulse across a marshy inland delta that provided a rich habitat. Subsequently the area was drained and converted into rich and productive farmland, with sugar beets being one of the prime products. The Wild Rice River is leveed throughout its lower reaches in order to protect farmland from inundation.

Both the severe flood of 1997 in the Red River Valley and prevailing low commodity prices have caused some of the farmland to be abandoned. An appropriate consolidation of abandoned farmland combined with setback levees can allow for the river to self-restore marshland habitat (Schneider, 2002). Farming can be expected to continue, however, and thus the remaining farms need to be protected. The low slopes of the bed of glacial Lake Agassiz create a natural depositional zone. Design of the setback levees must then be accompanied by the construction of a sediment budget, so as to determine a rate of marshland aggradation as a function of the degree of levee setback.

\section{Streams with altered flow regime}

Many streams in the western United States have highly altered flow regimes. In the case of the Trinity River, California, for example, nearly all of the flow above Lewiston is captured by a dam and diverted for consumptive purposes. A gravel-bed river such as the Trinity River requires floods to move and rework its gravel. It also needs a supply of gravel from upstream, which has been cut off by the dam. The absence of floods has led to the gradual pollution of gravel-bed habitat, including spawning grounds for salmonids, with fine-grained sediment that cannot be washed out by high flows. In addition, the bed surface has armored to a significant degree as the residual flows wash out the finer gravel without overturning the coarser gravel. Finally, the absence of floods has resulted in vegetal encroachment, and in particular encroachment by alders, which have served to substantially narrow the channel.

Attempts have been made to restore the gravel beds by a) dredging and "ripping" the bed with mechanical equipment to help remove the fines, and b) feeding fresh gravel to the sediment-starved river. No self-sustaining restoration of the river can be realized, however, without the release of some flood "flushing flows" from the Trinity Dam (Kondolf and Wilcock, 1996). Such flushing flows must be designed to provide as much restoration of river morphology and habitat as possible, while nevertheless maintaining a substantial supply of water for consumptive use. Such a problem is a natural one for the application of the latest techniques in sediment transport and morphodynamic modeling. An illustrative calculation is given below.

\section{A sample calculation}

The use of morphodynamic models in stream restoration is illustrated with a simple, hypothetical example of a gravel-bed stream. The example is nevertheless motivated by the case of the Trinity River described above. Calculations are performed with the transport relation of Wilcock and Crowe (2003). The river has a width of $60 \mathrm{~m}$. The "natural" flood hydrograph of the stream lasts 30 days per year; 
it is shown in Figure 6. The grain size distributions of the gravel substrate and sediment feed are given in Figure 7. The reach has a length of $10 \mathrm{~km}$. Assuming a "natural" bedload supply of 412,000 metric tons per year, the equilibrium "natural" bed slope is found to be 0.00260 ; the resulting self-formed "natural" grain size distribution of the bed surface is given in Figure 7.

Now at some time a dam is constructed, and most of the flow is diverted. The remaining flood hydrograph after diversion has a constant discharge, as shown in Figure 6. The sediment feed is reduced to 41 metric tons per year, i.e. almost vanishing, because it is being captured by the dam. The model is now run for 60 years. The final bed slope at the downstream end of the reach becomes 0.00230 , so that some bed degradation has occurred. The bed armors substantially due to flow diversion, as shown in Figure 7.

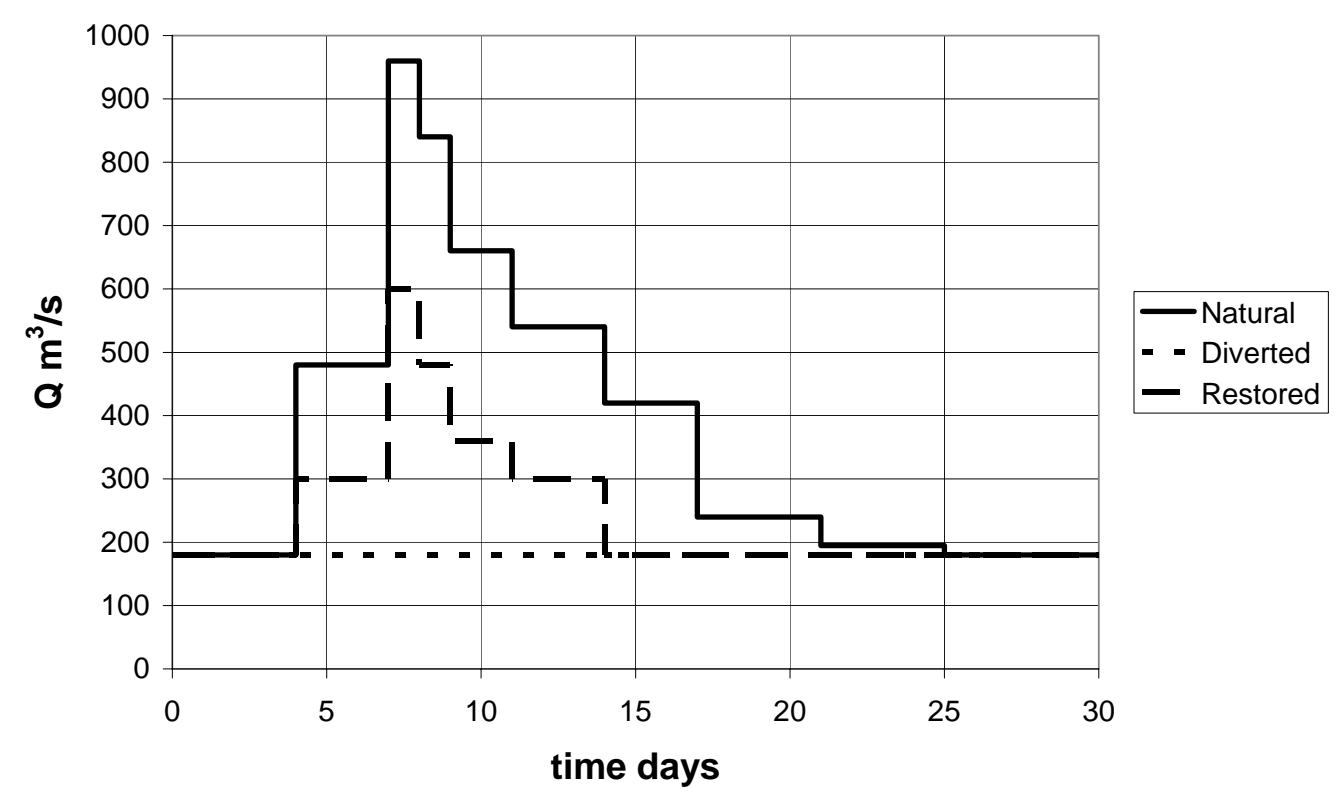

Figure 6. Flood discharge $\mathrm{Q}$ as a function of time for an annual 30-day flood hydrograph under a) natural conditions, b) water diversion by a dam and c) partial restoration of the natural hydrograph.

The final bed slope downstream bed slope surface grain size distribution associated with the flow diversion regime are now used as initial conditions for a further 60 years of calculation, during which part of the flood hydrograph is restored by augmented release from the dam, and sediment feed at a rate of 165,000 metric tons per year is implemented artificially. At the end of the 60-year period the bed slope at the downstream end has increased back to 0.00252 , i.e. not too far below its pre-diversion value. The surface grain size distribution at the downstream end at the end of 60 years of restored flood flow and sediment supply is shown in Figure 7. The surface layer has become finer, approaching its pre-diversion distribution.

The implication is that the scheme for restoring the river is successful in rendering the bed mobile again, and restoring a surface armor that is close to the "natural" value and much finer than the very coarse, immobile armor due to flow 
diversion and sediment cutoff by the dam. In addition, most of the bed degradation caused by the dam is recovered.

The cost of the scheme can be evaluated as follows. Under "natural" conditions, the total water passed by the dam by the annual 30-day flood hydrograph is $9.33 \times 10^{8}$ $\mathrm{m}^{3}$. Under the diversion regime of the dam the water passed by the dam during the annual 30-day flood period is $4.67 \times 10^{8} \mathrm{~m}^{3}$, leaving $4.67 \times 10^{8} \mathrm{~m}^{3}$ for consumption. Under the restored regime of the dam, the annual passage of flood water is $6.22 \times 10^{8}$ $\mathrm{m}^{3}$, leaving $3.11 \times 10^{8} \mathrm{~m}^{3}$ for consumptive purposes. That is, $2 / 3$ of the water consumed under the diversion regime is still available for consumption after restoration, with $1 / 3$ lost to flood releases. The cost of the restoration scheme is the cost of this lost water, plus the cost of implementing annual gravel feeding downstream, minus the benefits of the restoration itself.

The calculations for this example were performed using VBA (Visual Basic for Applications) code imbedded in an Excel workbook. The code is run from a GUI (Graphical User Interface) on a worksheet in the workbook. It is available at no cost from the author, who is developing a set of freeware pertaining to river morphodynamics.

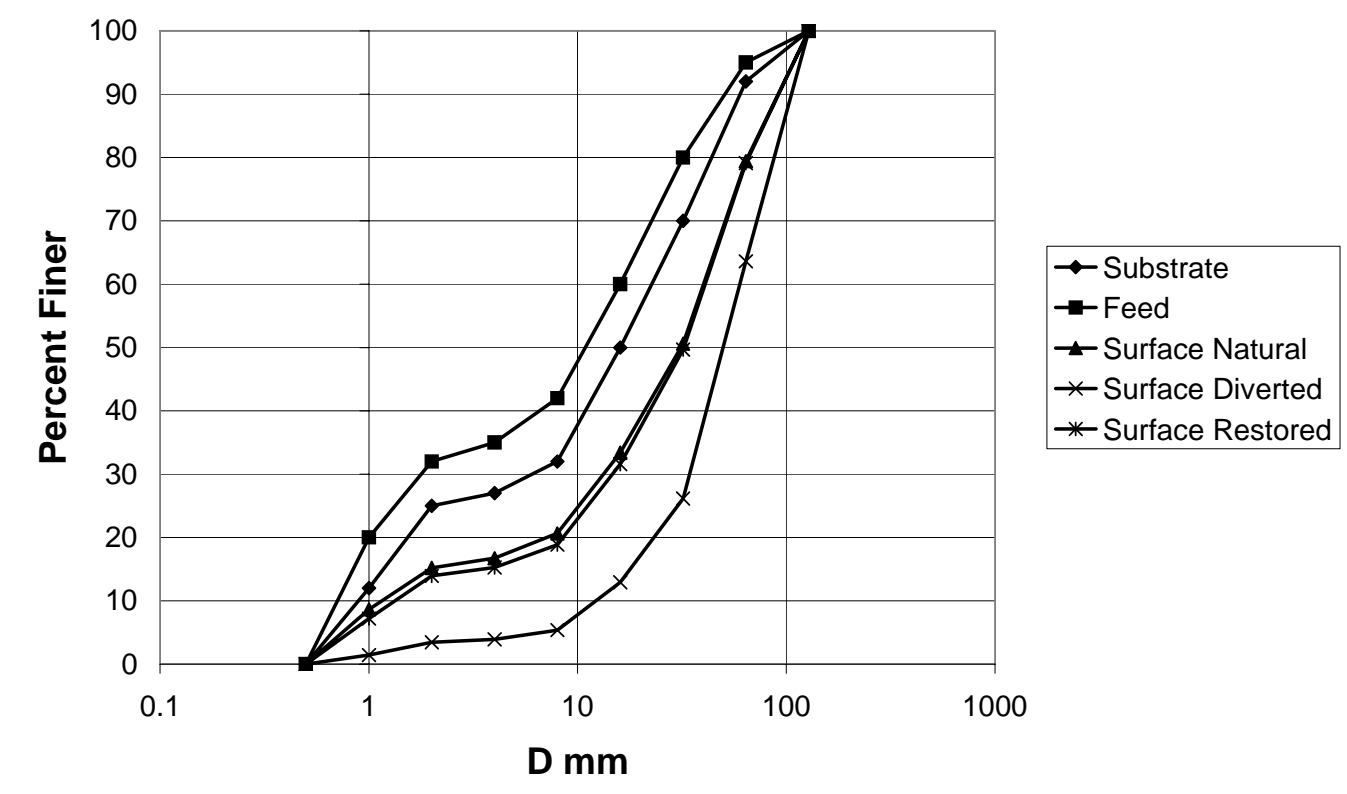

Figure 6. Grain size distributions of a) substrate, b) feed material, c) bed surface under natural conditions, d) bed surface after 60 years of flow diversion and sediment starvation and e) bed surface after 60 years of partially restored flood flow and sediment feed.

\section{Conclusions}

The construction of a sediment budget should be a part of many river restoration projects. Models of sediment transport and the resulting morphodynamics can provide useful information as to how to restore to the greatest extent possible the 
natural functionality of the stream. A broader distribution of morphodynamic models in a user-friendly format can serve to aid the process of technology transfer from the research community to the actual practitioners of river restoration.

This material is in part based upon work funded by the National Science Foundation STC Program under agreement number EAR-0120914.

\section{References}

Cui, Y., Parker, G., Lisle, T., Gott, J., Hansler, M., Pizzuto, J. E., Allmendinger, N. E. and Reed, J. M. (2003a) Sediment pulses in mountain rivers. Part 1. Experiments. Water Resources Research, 39(9), 1239, doi:10.1029/2002WR001803.

Cui, Y., Parker, G., Pizzuto, J. E. and Lisle, T. E. (2003b) Sediment pulses in mountain rivers. Part 2. Comparison between experiments and numerical predictions. Water Resources Research, 39(9), 1240, doi:10.1029/2002WR001805.

Cui, Y., Parker, G, Braudrick, C., Dietrich, W. E. and Cluer, B. (in press-a). "Dam Removal Express Assessment Models (DREAM). Part 1: Model development and validation.” Journal of Hydraulic Research.

Cui, Y., Braudrick, C., Dietrich, W. E., Cluer, B. and Parker G. (in press-a) "Dam Removal Express Assessment Models (DREAM). Part 2: Sample runs/sensitivity tests." Journal of Hydraulic Research.

Hunziker, R., and Jaeggi, M. N. R. (2002) "Grain sorting processes." Journal of Hydraulic Engineering, 128(12), 1060-1068.

Kondolf, G.M., and P.R. Wilcock. (1996). "The flushing flow problem: defining and evaluating objectives.” Water Resources Research. 32(8):2589-2599.

Lisle, T. E., Cui, Y., Parker, G., Pizzuto, J. E. and Dodd, A. (2001). "The dominance of dispersion in the evolution of bed material waves in gravel-bed rivers." Earth Surface Processes and Landforms, 26, 1409-1420.

Parker, G.. (1990). "Surface-based bedload transport relation for gravel rivers." Journal of Hydraulic Research, 28(4): 417-436.

Powell, D. M., I. Reid and Laronne, J. B. (2001) "Evolution of bedload grain-size distribution with increasing flow strength and the effect of flow duration on the caliber of bedload sediment yield in ephemeral gravel-bed rivers." Water Resources Research, 37(5), 1463-1474.

Schneider, M. (2002). A Geomorphic Study of the Wild Rice River, Minnesota and Implications for River Restoration. M.S. thesis, University of Minnesota, 90 p.

Wilcock, P. R., and Crowe, J. C. (2003). "Surface-based transport model for mixedsize sediment.” Journal of Hydraulic Engineering, 129(2), 120-128. 